\title{
The relationship between physical activity and food intake
}

\author{
Neil A. King* \\ BioPsychology Group, Department of Psychology, University of Leeds, Leeds LS2 9JT, UK
}

It is a commonly held belief that exercise (one method of inducing an energy deficit) causes a compensation in energy intake to match the exercise-induced energy expenditure. This could possibly lead to the belief that exercise is not a useful method of weight loss which could then be used as an excuse not to exercise. However, there is no compelling evidence to suggest that exercise drives hunger and energy intake to cause a compensation in food intake. Indeed, the evidence suggests interventions in energy expenditure are not compensated for by changes in energy intake at least in the short-term (see King et al. $1997 b$ for a review). This suggests only weak short-term coupling between energy expenditure and energy intake. However, since the negative energy balance could not continue indefinitely an equilibrium of energy intake and energy expenditure must occur at some stage. The exact time course (and mechanism) of such a compensatory change in energy intake is not yet known. A 'delayed' compensatory response to physical activity has been suggested (Edholm et al. 1955; Edholm, 1977), but this phenomenon has never been replicated.

One other issue concerns the effects of exercise on changes in food selection or food preferences. Another widely held belief is that exercise induces an increase in the selection of carbohydrates. The evidence for a short-term effect is not convincing, but in the long-term carbohydrate intake does increase with prolonged exercise (Wood et al. 1982). This effect could be biologically driven or occur as a result of changes of a psychological nature. At the present time some effects of exercise on appetite are clear whereas other aspects require more research. The interactions are likely to involve both physiological and psychological processes. With the renewed interest in physical activity for body weight control, it becomes increasingly important to understand more fully the effects of exercise on the control of appetite.

\section{Exercise and the expression of appetite}

A number of possible feeding responses to increased physical activity can be envisaged. First, an increase in food intake such that there is a compensatory rise in energy intake which could fully or partially match the energy expended. Second, a suppression of food intake, the socalled exercise-induced anorexia. Third, an alteration in food preference or (macronutrient) selection. Thus, exercise may potentially affect various aspects of eating patterns, including meal size, frequency of eating episodes, food choice and nutrient intake. The mechanism involved in these responses could be either physiologically- or psychologically-induced (or a combination of both).

Only a few investigations have been carried out to examine the relationship between exercise and food intake (for review, see King et al. 1997b), but there are many factors that could potentially influence the food intake response to exercise (see Table 1). The establishment of robust relationships between exercise and appetite is hindered by methodological problems with measuring food intake in human subjects. One problem is the considerable difficulty involved in accurately measuring food intake, especially in free-living circumstances using self-record food diaries (Prentice et al. 1986; Bandini et al. 1990; Livingstone et al. 1990). The errors in this procedure may mask any true exercise-induced changes in energy intake. Many studies reporting the effects of exercise on food intake have been conducted primarily to assess the capacity of exercise to induce changes in body weight and body composition, with food intake assessed only as an incidental measure. Using body weight as a predictor of

Table 1. Potential factors that influence food intake response to exercise in human studies

\begin{tabular}{l} 
Exercise \\
Intensity \\
Mode \\
Duration \\
Periodicity \\
Supervision \\
Subjects \\
Age \\
Gender \\
Fitness level ( $V_{\mathrm{O}_{2} \text { max }}$ ) \\
Body composition \\
Dietary status (restrained or disinhibited) \\
Cognitions or beliefs \\
Miscellaneous \\
Measurement of food intake \\
Measurement environment \\
\hline
\end{tabular}

$\mathrm{V}_{\mathrm{O}_{2} \max }$, maximum $\mathrm{O}_{2}$ uptake. 
the effects of exercise on energy intake can be misleading, especially since exercise has been reported to have varying effects on fat-free mass and fat mass (Leon et al. 1979; Despres et al. 1985; Tremblay et al. 1985; Nieman et al. 1990). In order to assess accurately the effects of exercise on food intake, the measurement should be made directly rather than estimated.

\section{Is there a coupling between activity-induced energy expenditure and energy intake?}

A traditional view of this issue is based on the premise that energy balance is regulated. Thus, an increase in energy expenditure will lead to an obligatory compensatory rise in energy intake. However, this view must be supported by experimental evidence.

\section{Short-term interactions}

It is a common sense view that exercise generates an increase in hunger and a drive to eat. It is also a truism that refraining from eating prevents energy entering the biological system, whilst doing physical activity causes energy to leave the system. At a given time, therefore, failing to eat (when a meal is usually taken) or doing exercise (when it normally would not have been done) should each create a net negative energy balance. There are many examples in the literature of food restriction (skipping of a meal) or an energy differential (between two meals of different sizes) giving rise to hunger and increased food intake (Lawton et al. 1993; Green et al.
1994; Delargy et al. 1995). The response to this type of energy deficit appears logical and is well accepted. The relationship between exercise-induced energy deficits and food consumption has been subjected to much scrutiny, and the evidence suggests that there is no increase in hunger or energy intake as a result of an exercise-induced energy deficit (Reger et al. 1986; Reger \& Alison, 1987; Thompson et al. 1988; Kissileff et al. 1990; King et al. 1994; King \& Blundell, 1995). To our knowledge only one study has created energy deficits using both methods (food deprivation and exercise-induced) in a single study using the same individuals (Hubert et al. 1997). This study confirmed that the energy deficit created by food deprivation (meal omission) significantly increased hunger (see Fig. 1) and energy intake, whereas the exercise-induced energy deficit did not. This finding suggests that the effects of food deprivation are quite different from the effects of a bout of exercise, and that there appears to be a weak shortterm coupling between exercise-induced energy expenditure and energy intake.

In contrast to the idea that a compensatory rise in hunger should follow exercise, many studies have shown that following a bout of intense exercise ( $>60 \%$ maximum $\mathrm{O}_{2}$ uptake) hunger is actually suppressed (Reger et al. 1986; Reger \& Alison, 1987; Thompson et al. 1988; Kissileff et al. 1990; King et al. 1994; King \& Blundell, 1995). However, this suppression of hunger is rather short-lived (see Fig. 2) there appears to be no enduring effect on food intake. This phenomenon is now referred to as exerciseinduced anorexia (King et al. 1994). With more-severe and longer-term physical activity the reduction in the drive to eat may be more persistent (Milon et al. 1996).

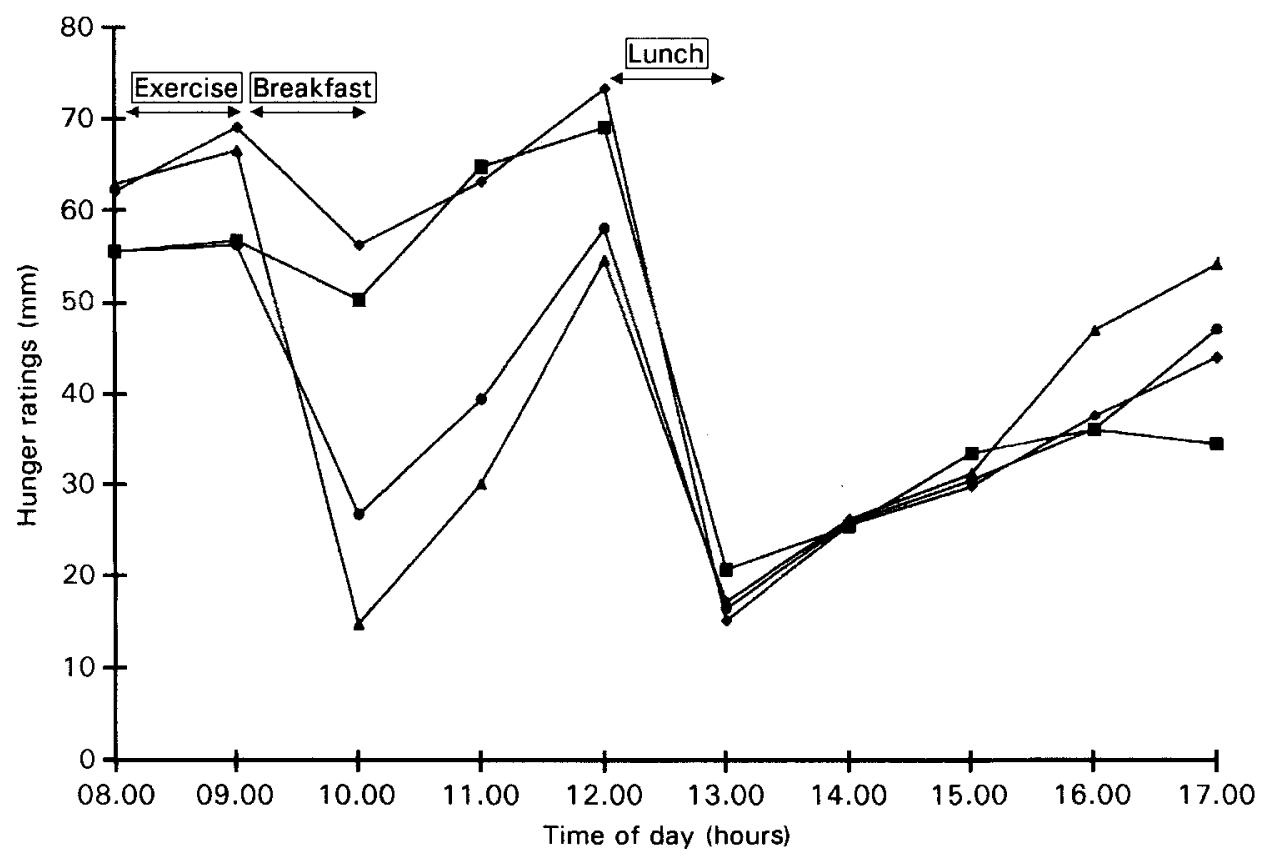

Fig. 1. Hunger profiles (hunger ratings; subjective feeling of hunger) following energy deficits induced by two different methods (exercise and/or food deprivation). Hunger is significantly lowered $(P<0.005)$ for $3 \mathrm{~h}$ following a high-energy breakfast compared with a low-energy breakfast at 09.00 hours. There was no significant difference in hunger response following a bout of exercise compared with no exercise at 08.00 hours. ( $\bullet$ No exercise, low-energy breakfast; ( $\square$ ), exercise, low-energy breakfast; $(\boldsymbol{\Delta})$, no exercise, high-energy breakfast; $(\boldsymbol{\bullet})$, exercise, high-energy breakfast. 


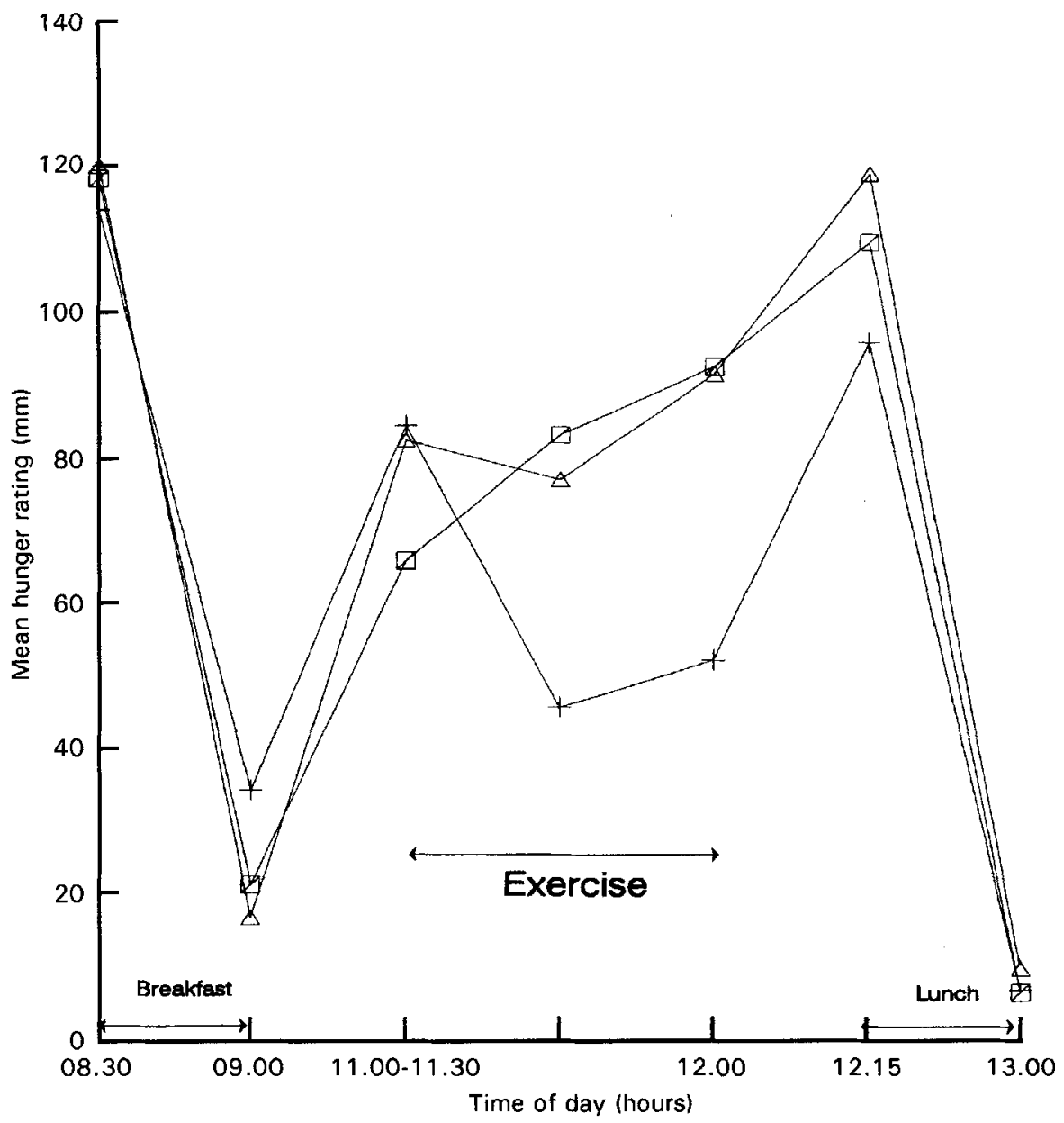

Fig. 2. Short-lived suppression of hunger (hunger rating; subjective feeling of hunger) induced by a bout of high-intensity exercise $(+)$, compared with a bout of low-intensity exercise $(\Delta)$ and a period of no-exercise ( $\square$ ).

Since food intake is unaffected by the exercise in the majority of short-term studies the authors have concluded that exercise does not affect energy intake. However, in most of these studies the energy cost of the exercise was not taken into account, hence the results have been interpreted to mean that exercise is not a useful modulator of energy balance (because intake is not adjusted). If the energy cost of the exercise is accounted for, the 'relative energy intake' can be calculated (energy intake - energy expended). When this calculation is made exercise does give rise to an overall energy deficit (but this depends on the energy density of the food consumed). Hence, it is important to examine the effects of exercise in respect to 'absolute' energy intake and 'relative' energy intake.

Overall, the evidence points to a rather weak coupling between energy intake and energy expenditure. It could be argued that the exercise (a single bout) in the previously described studies is too small to have any marked effect. However, even with two intense exercise sessions in the same day (combined net cost approximately $4.5 \mathrm{MJ}$ ), hunger and energy intake are unaffected on the day of, and the day immediately after, exercise, compared with days of no exercise (King et al. 1997a). It is also possible that some studies do not track energy intake for long enough during or after the exercise intervention and consequently miss any compensatory effect. The classic work frequently referred to is that of Edholm et al. (1955). It was demonstrated that although there was no relationship between energy expenditure and energy intake on the same day, there was a positive relationship between energy expenditure on $1 \mathrm{~d}$ and energy intake $2 \mathrm{~d}$ later. This led Edholm (1977) to remark that 'We do not eat for today but for the day before yesterday'. Despite subsequent attempts the same authors failed to replicate this finding (Edholm, 1977). Therefore, this lag of $2 \mathrm{~d}$ between energy expenditure and energy intake is somewhat isolated and has been criticized (Durnin, 1961). In fact, this phenomenon of a delayed compensatory response has recently been subjected to detailed scrutiny (de Castro, 1997), again resulting in a failure to find any relationship between energy expenditure on $1 \mathrm{~d}$ and energy intake on subsequent days. In further attempts to investigate this phenomenon, we have recently accurately tracked food intake for $3 \mathrm{~d}$ after a high dose of exercise (net cost approximately $5 \mathrm{MJ}$ ) and found no 'delayed' compensation in energy intake (see Fig. 3) and no relationship between exercise-induced energy expenditure and energy intake (NA King, unpublished results). Indeed, individuals appeared to eat to a particular level which was unaffected by days of lower activity (rest days) and $1 \mathrm{~d}$ of very high activity (two substantial periods of exercise). 


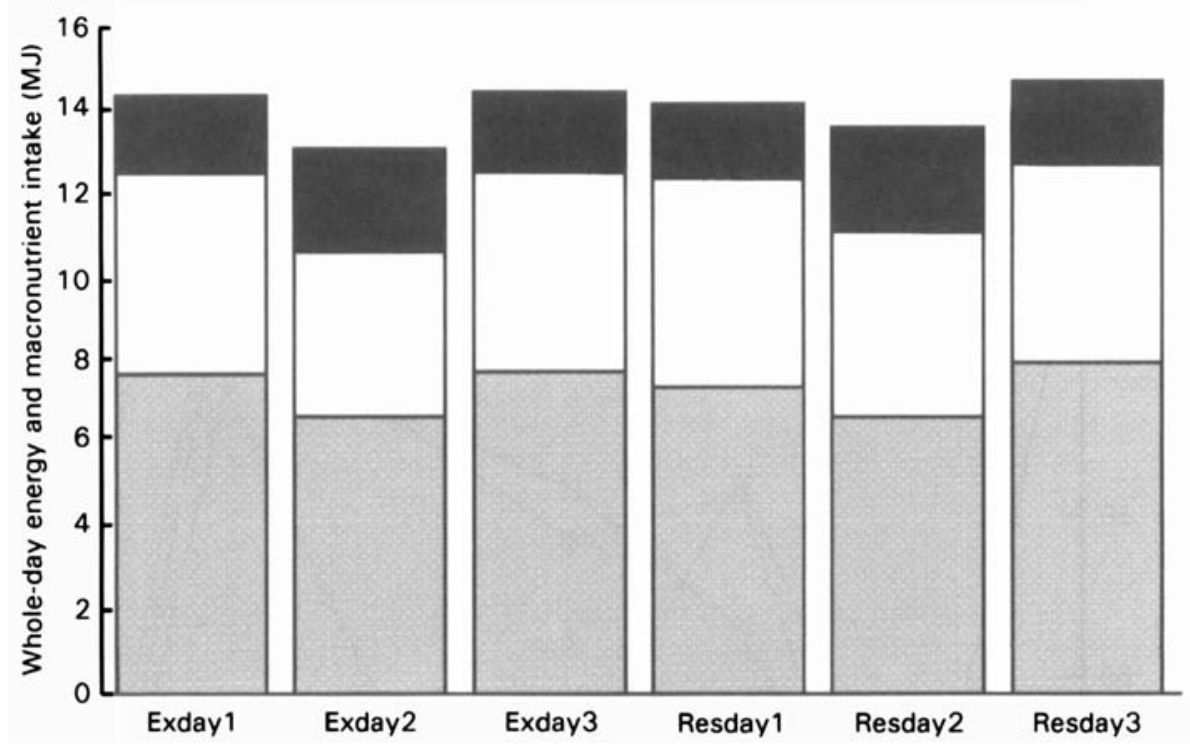

Fig. 3. Energy intake (MJ) on the day of high-dose (net cost $4200 \mathrm{~kJ}$ ) exercise (Exday1), and the $2 \mathrm{~d}$ after (Exday2 and Exday3), compared with $3 \mathrm{~d}$ of no exercise (Resday1, Resday2, Resday3). ( $\square$ ), Protein; $\square$, fat; (圈), carbohydrate.

Why does a reduction in physical activity not downregulate energy intake? Recent findings have confirmed that energy intake remains at some stable preferred level even when energy expenditure is manipulated. In two separate studies (using two separate sets of individuals), in which identical ad libitum diets were fed, energy expenditure and energy intake were measured either in a free-living environment (Stubbs et al. 1995b) or in a whole body calorimeter (Stubbs et al. 1995a). Subjects ate virtually identical amounts in both situations, despite the energy expenditures being substantially different (difference between free-living active lifestyle and enforced sedation in the calorimeter). It should be kept in mind that these deductions were not based on a within-subjects single experiment, but were made on the basis of separate outcomes from two independent studies. Nevertheless, it is apparent that hunger and the pattern of eating are not closely related to perturbations in energy expenditure induced by large adjustments in physical activity. It is obvious that a lack of coupling between energy expenditure and energy intake cannot continue indefinitely. Eventually, a new balance must be achieved between intake and expenditure if weight is stabilized. At some stage, therefore, energy intake must increase to compensate for the exercise-induced energy deficit. However, under extreme circumstances (endurance exploring or swimming), in some situations individuals can sustain a negative energy balance (on average between 2 and $7 \mathrm{MJ} / \mathrm{d}$ ) for up to 48 (Stroud $e t$ al. 1993) or 55 (Milon et al. 1996) d.

Individuals appear to eat within certain limits that are controlled partly by pre-absorptive physiological responses and partly by social convention. The pattern of eating appears to be fairly resistant to some gross changes in energy expenditure and metabolism. Perhaps the body does not possess an automatic, rapidly-acting mechanism which matches energy intake to a calculated positive or negative energy balance. This relationship between activity-induced energy expenditure and food intake may have to be learned. Indeed, using the Tour de France cyclists as an example, it is clear that some behavioural adaptations do occur (Westerterp et al. 1986), because in these individuals there is a tight regulation between energy expenditure and energy intake. However, it is worth noting that these individuals are aware that if energy intake is insufficient, performance will be impaired. Thus, individuals engaged in regular heavy physical activity may eat both in anticipation of future energy requirements and in response to energy expended. Hence, under these circumstances the exerciseinduced changes probably result from a combination of metabolic and behavioural factors. In the short term, there is probably insufficient opportunity to increase energy intake due to a combination of physiological limitations and social convention. Recently, Hill et al. (1995) suggested that a period of transition (disruption) takes place before any new steady state is reached. The period of imbalance is probably caused by a combination of behavioural and physiological responses.

\section{Long-term interactions}

In general, most studies support the view that there is little indication of complete compensation in energy intake in response to increased levels of physical activity (Dempsey, 1964; Leon et al. 1979; Woo et al. 1982a,b; DicksonParnell \& Zeichner, 1985; McGowan et al. 1986; Tagliaferro et al. 1986; Andersson et al. 1991). However, some studies have reported a compensatory increase (Passmore et al. 1952; Durrant et al. 1982; Wood et al. 1982; Woo \& Pi-Sunyer, 1985). The absence of a compensatory increase in energy intake in response to increases in exercise may be counterintuitive, especially when cross-sectional data suggest a positive relationship between energy expenditure and energy intake (Blair et al. 
1981; Tremblay et al. 1983; Reggiani et al. 1984; Maughan et al. 1989; Broeder et al. 1992). It is likely that a tight coupling between energy intake and energy expenditure only exists at very high levels of physical activity. In physically-active individuals, therefore, there is a higher energy 'flux'. As noted earlier, this persistent high level of physical activity is likely to entrain a higher energy intake.

\section{Does the energy (and nutrient) demand created by exercise stimulate a drive for a particular macronutrient?}

The natural hypothesis would be that energy reserves utilized most severely during exercise (e.g. glycogen) would stimulate a drive for a particular nutrient (e.g. carbohydrate). However, for such a mechanism to exist a physiological signal reflecting glycogen depletion or carbohydrate oxidation must first be generated and second be detected. This biological process then has to manifest itself in the form of eating behaviour. One of the oldest problems in physiological psychology concerns the mechanisms by which physiological needs are translated into behaviour (Blundell, 1975). It has been suggested that energy-intake responses are more sensitive to fluctuations in carbohydrate balance than fat balance, due to the large differences in the magnitude of the body's storage capacity for each of these two macronutrients (Flatt, 1987). It can be hypothesized that since exercise will alter the storage and oxidation status of fat and carbohydrate (depending on exercise intensity and duration), then exercise has the potential to influence the intake of both these macronutrients. On the basis of a simple depletion hypothesis, individuals would be expected to replace the substrate predominantly utilized during exercise. It follows that exercise-induced changes in food selection would be associated with the substrate mix oxidized during exercise; this in turn being influenced by the intensity and duration of the exercise session. This phenomenon of a physiologically-induced drive to increase carbohydrate selection after exercise also originates from anecdotal evidence that athletes consume diets high in carbohydrate in order to maintain a high level of glycogen stores (Hultman \& Bergstrom, 1967; Kirwan et al. 1988). Animal studies (Flatt, 1987) suggest that the RQ generated during exercise will influence the food quotient (RQ of food consumed) of the food chosen. Does this process also work in human subjects operating under restricting experimental protocols, or under natural circumstances free of any protocol? Does food quotient match RQ?

This phenomenon is based on the concept that physiological changes will have a strong influence on food selection (i.e. a strong coupling between physiology and behaviour), and ignores the possibility that food choice can also be strongly influenced by environmental contingencies and psychological determinants (Blundell, 1991). It could be argued that food choice is mainly determined by subjective preferences which have built up over the years, and may be resistant to short-term perturbations in exercise-induced metabolic alterations. This could be why studies have failed to show that exercise has any short-term effect on carbohydrate intake (Reger et al. 1986; Thompson et al. 1988; King et al. 1994; Tremblay et al. 1994; King \& Blundell, 1995), with one exception (Verger et al. 1992). In light of the recent suggestion that a period of transition must occur before interventions in physical activity have any profound effect on energy and nutrient intake (Hill et al. 1995), short-term studies are unlikely to detect any close coupling. However, it is possible that an increase in carbohydrate intake would take place in the long term. Indeed, there is evidence to suggest that carbohydrate intake does increase in response to prolonged physical activity (Wood et al. 1982). This increase in carbohydrate intake is probably as a result of a combination of physiological and psychological responses. In other words, exercise creates a disposition to seek carbohydrate but this is enhanced by conscious recognition that a high carbohydrate intake will be beneficial.

\section{Exercise and cognitive factors}

Recently it has been speculated that psychological factors (e.g. concerning the tendency to diet) could have a significant influence on the food intake response to exercise (Hill et al. 1995). Those tendencies can be measured by validated psychometric scales (e.g. three factor eating questionnaire; Stunkard \& Messick, 1985) and allow individuals to be evaluated on factors such as dietary restraint (inhibition of eating) and disinhibition (tendency to give in to eating). It has been suggested that an individual's 'cognitive approach to eating and dieting' would influence the eating response to exercise (Hill et al. 1995). Of course, when faced with a challenge such as exercise, individuals do have different objectives including a wish to lose weight or to improve athletic performance. Given that people are capable of altering their eating behaviour to meet particular objectives (Blundell \& King, 1996), the deliberate control over food intake with respect to exercise should not be ignored. Although very little work has been done on this issue, it has been demonstrated that dietary-restrained women do not alter their eating behaviour after a period of intense exercise (Lluch et al. 1997); a response that is similar to that of a group of unrestrained females (King et al. 1996). This is in line with predictions of Hill et al. (1995) that energy intake would be unresponsive to exercise in a group of non-dieting restrained eaters.

Although exercise failed to have any effect on energy intake in either the unrestrained or restrained females in these two studies, further analysis of the combined data (Lluch et al. 1998) revealed a very interesting relationship between dietary restraint and food intake. There was a significant positive relationship ( $r \quad 0.54)$ between dietary restraint and energy intake following a period of no exercise (rest period), but not after a bout of exercise (see Fig. 4(a and b)). This suggests that energy intake is significantly influenced by the degree of dietary restraint in the absence of exercise only. Thus, following a period of exercise energy intake appears to be 'deliberately' controlled, whereas in the absence of exercise (i.e. following a period of rest) this 'deliberate' control is 

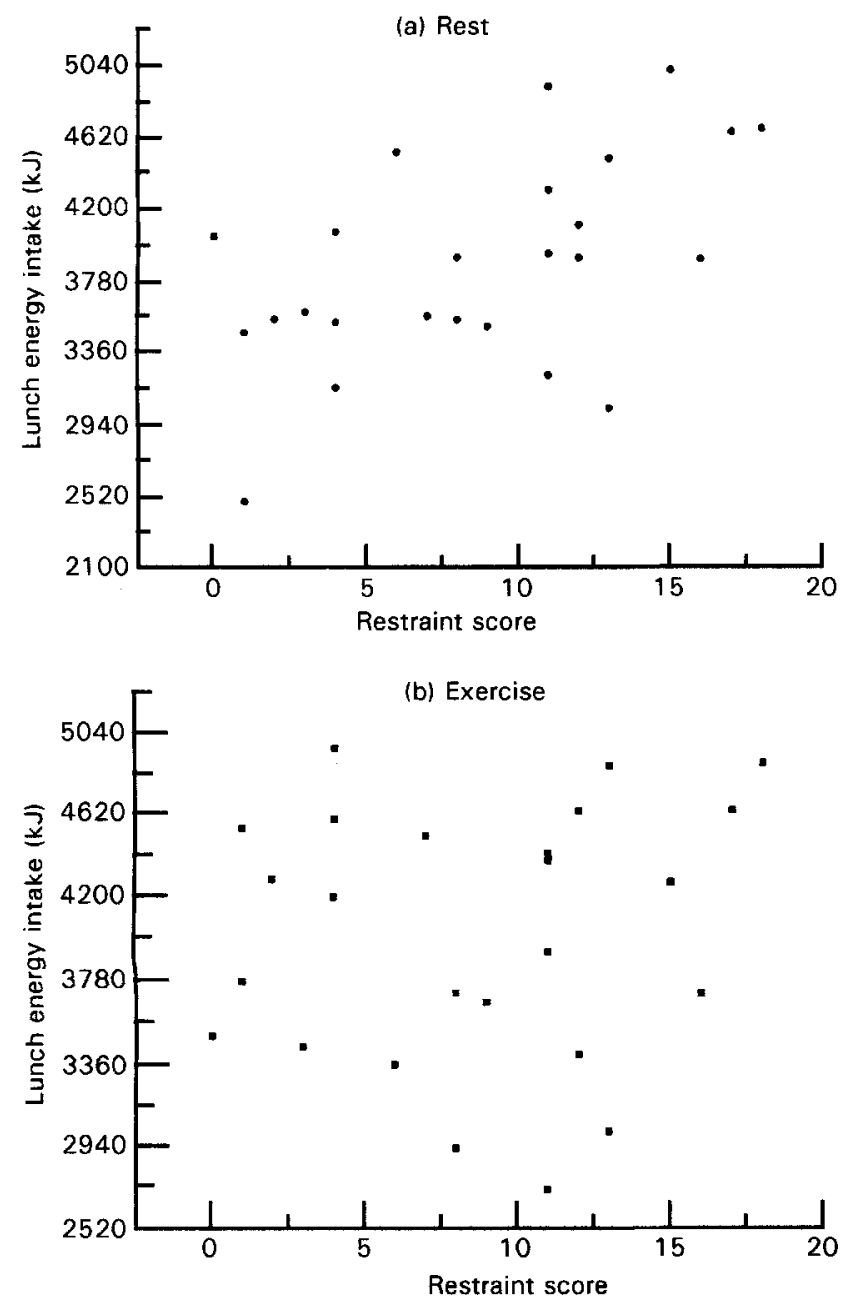

Fig. 4. Relationship between dietary restraint score (measure of an individual's motivation to consciously control his (her) eating habits) and energy intake following a period of rest and exercise. There was a significant correlation $(r 0.54, P<0.01)$ between dietary restraint and test meal energy intake in the absence of exercise (a), but not atter exercise $(r 0.09)(b)$.

relaxed and energy intake increases. These data indicate that there is much to be learned from further investigations of the relationship between cognitions and exercise.

It should be kept in mind, therefore, that following exercise the deliberate and volitional control over eating behaviour could have a significant influence. In turn, this would obviously override any potential physiological coupling between energy expenditure and energy intake. One example of this is the individual who feels the desire to reward him/herself following an exercise session by consuming foods that would normally be considered 'forbidden' (probably very palatable and with high energy density). One phenomenon that has recently been confirmed is that selecting high-fat (energy dense) foods after exercise will completely reverse the negative energy balance created by exercise (Tremblay et al. 1994; King \& Blundell, 1995; King et al. 1996). Thus, exercise does not permit people to abandon any restraint over eating, and to freely indulge the available foods. If individuals do reward themselves after exercise by selecting high-energy- density foods, this obviously jeopardizes the beneficial effects (negative energy balance) of exercise.

\section{Conclusion}

Despite the commonly-held belief that the energy demand created by exercise automatically generates a drive to eat, the evidence for this is weak. Indeed, the argument formed on the basis of experimental outcomes is counterintuitive. Overall, there is no compelling evidence to suggest that the energy deficit created by exercise leads to a compensatory increase in energy intake. Rather the evidence suggests that there is a weak short-term coupling between energy expenditure and energy intake, probably because the behavioural acts of food intake are held in place by environmental contingencies and rapidly-acting short-term post-ingestive physiological responses arising from eating itself. Even in the long term, most of the evidence suggests that energy intake is relatively immune to the metabolic effects generated by physical activity. However under normal circumstances, this lack of coupling cannot continue indefinitely and at some stage a regulatory mechanism must 'kick-in' to prevent a continuing energy deficit. Part of this regulatory process could involve a tendency for food quotient to follow RQ. However, the physiological and psychobiological threshold that has to be reached before energy intake begins to rise or changes in food choice occur has yet to be determined. This weak coupling between energy expenditure and intake has positive implications for the use of physical activity in weight loss or weight maintenance. However, the positive effects do depend on the capacity to maintain compliance over two forms of behaviour. First, compliance over eating behaviour to guard against over-indulgence (particularly on high-energy-density or high-fat foods), and, second, compliance over the exercise regimen itself.

\section{Acknowledgements}

This review was prepared during the tenure of research funding from the Biotechnology and Biological Sciences Research Council (BBSRC) (F02501). I am grateful to John Blundell and Anne Lluch for their scientific contribution.

\section{References}

Andersson B, Xu X, Rebuffee-Scrive M, Terning K, Krotkiewski M \& Bjorntorp P (1991) The effects of exercise training on body composition and metabolism in men and women. International Journal of Obesity 15, 75-81.

Bandini LG, Schoeller DA, Cyr HN \& Dietz WH (1990) Validity of reported energy intake in obese and non-obese adolescents. American Joumal of Clinical Nutrition 52, 421-425.

Blair SN, Ellsworth NM, Haskell WL, Stern MP, Farquar JW \& Wood PD (1981) Comparison of nutrient intake in middle-aged men and women runners and controls. Medicine and Science in Sports and Exercise 13, 310-315.

Blundell JE (1975) Physiological Psychology. London: Methuen.

Blundell JE (1991) The biology of appetite. Clinical Applied Nutrition 1, 21-31. 
Blundell JE \& King NA (1996) Overconsumption as a cause of weight gain: behavioural-physiological interactions in the control of food intake (appetite). In The Origins and Consequences of Obesity, pp. 138-158 [DJ Chadwick and G Cardew, editors]. Chichester: Wiley.

Broeder CE, Burrhus KA, Svanevik LS \& Wilmore JH (1992) The effects of aerobic fitness on resting metabolic rate. American Journal of Clinical Nutrition 55, 795-801.

de Castro J (1997) How can energy balance be achieved by freeliving human subjects? Proceedings of the Nutrition Society 56, $1-14$.

Delargy HD, Burley VJ, Sullivan KR, Fletcher RJ \& Blundell JE (1995) Effects of different soluble:insoluble fibre ratios at breakfast on 24-h pattern of dietary intake and satiety. European Journal of Clinical Nutrition 49, 754-766.

Dempsey JA (1964) Anthropometrical measurements on obese and nonobese young men undergoing a program of vigorous physical exercise. Research Quarterly 35, 275-287.

Despres JP, Bouchard C, Tremblay A, Savard R \& Marcotte M (1985) Effects of aerobic training on fat distribution in male subjects. Medicine and Science in Sports and Exercise 17, 113118.

Dickson-Parnell BE \& Zeichner A (1985) Effects of a short-term exercise program on caloric consumption. Health Psychology 4, 437-448.

Durnin JVGA (1961) Appetite and the relationship between expenditure and intake of calories in man. Journal of Physiology 156, 294-306.

Durrant ML, Royston PJ \& Wloch RT (1982) Effect of exercise on energy intake and eating patterns in lean and obese humans. Physiology and Behavior 29, 449-454.

Edholm OG (1977) Energy balance in man. Journal of Human Nutrition 31, 413-431.

Edholm OG, Fletcher JG, Widdowson EM \& McCance RA (1955) The energy expenditure and food intake of individual men. British Journal of Nutrition 9, 286-300.

Flatt JP (1987) Dietary fat, carbohydrate balance, and weight maintenance: effects of exercise. American Journal of Clinical Nutrition 45, 296-306.

Green SM, Burley VJ \& Blundell JE (1994) Effect of fat- and sucrose-containing foods on the size of eating episodes and energy intake in lean males: potential for causing overconsumption. European Journal of Clinical Nutrition 48, 547-555.

Hill OJ, Melby C, Johnson SL \& Peters JC (1995) Physical activity and energy requirements. American Journal of Clinical Nutrition 62, Suppl., 1059S-1066S.

Hubert P, King NA \& Blundell JE (1997) Uncoupling the effects of energy expenditure and energy intake: appetite response to short-term energy deficit induced by meal omission and physical activity. International Journal of Obesity 21, Suppl., P125.

Hultman E \& Bergstrom J (1967) Muscle glycogen resynthesis in relation to diet studied in normal subjects. Acta Medica Scandinavica 182, 109-117.

King NA \& Blundell JE (1995) High-fat foods overcome the energy expenditure due to exercise after cycling and running. European Journal of Clinical Nutrition 49, 114-123.

King NA, Burley VJ \& Blundell JE (1994) Exercise-induced suppression of appetite: Effects on food intake and implications for energy balance. European Journal of Clinical Nutrition $\mathbf{4 8}$, 715-724.

King NA, Lluch A, Stubbs RJ \& Blundell JE (1997a) High dose exercise does not increase hunger or energy intake in free living males. European Journal of Clinical Nutrition 51, 478-483.

King NA, Snell L, Smith RD \& Blundell JE (1996) Effects of short-term exercise on appetite response in unrestrained females. European Journal of Clinical Nutrition 50, 663-667.
King NA, Tremblay A \& Blundell JE (1997b) Effects of exercise on appetite control: implications for energy balance. Medicine and Science in Sports and Exercise 29, 1076-1089.

Kirwan JP, Costill DL, Mitchell JB, Houmard JA, Glynn MG, Fink WJ \& Beltz JD (1988) Carbohydrate balance in competitive runners during successive days of intense training. Journal of Applied Physiology 65, 2601-2606.

Kissileff HR, Pi-Sunyer XF, Segal K, Meltzer S \& Foelsch PA (1990) Acute effects of exercise on food intake in obese and non-obese women. American Journal of Clinical Nutrition 52 , 240-245.

Lawton CL, Burley VJ, Wales JK \& Blundell JE (1993) Dietary fat and appetite control in obese subjects: weak effects on satiation and satiety. International Journal of Obesity 17, 409 416.

Leon AS, Conrad J, Hunninghake DB \& Serfass R (1979) Effects of a vigorous walking program on body composition and lipid metabolism of obese young men. American Journal of Clinical Nutrition 33, 1776-1787.

Livingstone MBE, Prentice AM, Strain JJ, Coward WA, Black AE, Barker ME, McKenna PG \& Whitehead RG (1990) Accuracy of weighed dietary records in studies of diet and health. British Medical Journal 300, 708-712.

Lluch A, King NA, Lipsey Z \& Blundell JE (1997) Exercise enhances palatability of food, but does not increase food consumption, in lean restrained females. International Journal of Obesity 21, Suppl., S129.

Lluch A, King NA, Lipsey Z \& Blundell JE (1998) Comparison of the short-term effects of exercise on food hedonics and food consumption in dietary restrained and unrestrained females. Proceedings of the Nutrition Society 57, 20A.

McGowan CR, Epstein LH, Kupfer DJ, Bulik CM \& Robertson RJ (1986) The effects of exercise on non-restricted caloric intake in male joggers. Appetite 7, 97-105.

Maughan RJ, Robertson JD \& Bruce AC (1989) Dietary energy and carbohydrate intakes of runners in relation to training load. Proceedings of the Nutrition Society 48, 170A.

Milon H, Decarli B, Scmitt L, Cambray MC \& Willemin S (1996) Traversée de l'Atlantique à la nage: alimentation et bilan nutritionnel (Swimming across the Atlantic: diet and nutritional balance). Cahiers de Nutrition et de Diététique 31, 51-57.

Nieman DC, Haig JL, Fairchild KS, DeGuia ED, Dizon GP \& Register UD (1990) Reducing-diet and exercise-training effects on serum lipids and lipoproteins in mildly obese women. American Journal of Clinical Nutrition 52, 640-645.

Passmore R, Thomson JG, Warnock GM, Dixon CM, Kitchin AH, Smith G, Vaughan MC \& Watt JA (1952) A balance sheet of the estimation of energy intake and energy expenditure as measured by indirect calorimetry using the Kofranyi-Michaelis calorimeter. British Journal of Nutrition 6, 1253-1265.

Prentice AM, Black AE, Coward WA, Davies HL, Goldberg GR, Murgatroyd PR, Ashford J, Sawyer M \& Whitehead RG (1986) High levels of energy expenditure in obese women. British Medical Journal 292, 983-987.

Reger WE \& Alison TG (1987) Exercise and appetite. Medicine and Science in Sports and Exercise 19, S38.

Reger WE, Allison TA \& Kurucz RL (1986) Exercise, postexercise metabolic rate and appetite. Sport Health and Nutrition 2, 117-123.

Reggiani E, Bertolini S, Chiodini G, Elicio N, Montanari D, Valice S, Zannini G, Baruzzo D, Montagna G, Pistocchi G, Lassa G \& Grace S (1984) Effects of physical activity and diet on lipemic risk factors for atherosclerosis in women. International Journal of Sports Medicine 5, 183-186.

Stroud MA, Coward WA \& Sawyer MB (1993) Measurements of energy expenditure using isotope-labelled water during an 
Arctic expedition. European Journal of Applied Physiology and Occupational Physiology 67, 375-379.

Stubbs RJ, Harbron CG, Murgatroyd PR \& Prentice AM (1995a) Covert manipulation of dietary fat and energy density: effect on substrate flux and food intake in men eating ad libitum. American Journal of Clinical Nutrition 62, 316-329.

Stubbs RJ, Ritz P, Coward WA \& Prentice AM (1995b) Covert manipulation of the ratio of dietary fat to carbohydrate and energy density: effect on food intake and energy balance in free-living men eating ad libitum. American Journal of Clinical Nutrition 62, 330-337.

Stunkard AJ \& Messick S (1985) The three factor eating questionnaire to measure dietary restraint, disinhibition and hunger. Journal of Psychosometric Research 29, 71-83.

Tagliaferro AR, Kertzer R, Davis JR, Janson C \& Tses SK (1986) Effects of exercise-training on the thermic effect of food and body fatness of adult women. Physiology and Behavior 38, 703-710.

Thompson DA, Wolfe LA \& Eikelboom R (1988) Acute effects of exercise intensity on appetite in young men. Medicine and Science in Sports and Exercise 20, 222-227.

Tremblay A, Almeras N, Boer J, Kranenbarg EK \& Despres JP (1994) Diet composition and postexercise energy balance. American Journal of Clinical Nutrition 59, 975979.

Tremblay A, Despres JP \& Bouchard C (1985) The effects of exercise-training on energy balance and adipose tissue morphology and metabolism. Sports Medicine 2, 223233.

Tremblay A, Leblanc C, Sevigny J, Savoie JP \& Bouchard C (1983) The relationship between energy intake and expenditure: A sex difference. In Health Risk Estimation, Risk Reduction and Health Promotion, pp. 115-119 [M Landry, editor]. Ottawa: Canadian Public Health Association.

Verger P, Lanteaume MT \& Louis-Sylvestre J (1992) Human intake and choice of foods at intervals after exercise. Appetite 1 , $1-7$.

Westerterp KR, Saris WHM, Van Es M \& Ten Hoor F (1986) Use of doubly labelled water technique in humans during heavy sustained exercise. Journal of Applied Physiology 61, 21622167.

Woo R, Garrow JS \& Pi-Sunyer FX (1982a) Voluntary food intake during prolonged exercise in obese women. American Journal of Clinical Nutrition 36, 478-484.

Woo R, Garrow JS \& Pi-Sunyer FX (1982b) Effect of exercise on spontaneous calorie intake in obesity. American Journal of Clinical Nutrition 36, 470-477.

Woo R \& Pi-Sunyer FX (1985) Effect of increased physical activity on voluntary intake in lean women. Metabolism 34, 836-841.

Wood PD, Haskell WL \& Terry RB (1982) Effects of a two-year running program on plasma lipoproteins, body fat and dietary intake in initially sedentary men. Medicine and Science in Sports and Exercise 14, 104 Abstr. 